\title{
¿Por qué estudiar los miedos desde la antropología?
}

\author{
Andrea Boscoboinik \\ Université de Fribourg \\ andrea.boscoboinik@unifr.ch
}

Resumen: El miedo es una emoción individual, pero también puede ser una experiencia social, colectiva y compartida. Sus múltiples dimensiones permiten que se la pueda analizar con diferentes perspectivas. Las emociones son verdaderamente un tema interdisciplinario que se puede estudiar desde distintos ángulos, tanto desde las ciencias naturales como de las sociales y culturales.

Palabras clave: antropología del miedo; miedos colectivos y sociales; inseguridad; sistemas acusatorios; milenarismos.

Abstract: Fear is an emotion experienced by the individual, but it can be a social, collective and shared experience. Its multiple dimensions mean that it can be analysed from different perspectives. Emotions are truly an interdisciplinary subject that can studied from various angles, including the natural sciences and the social and cultural sciences.

Keywords: anthropology of fear; collective and social fears; insecurity; accusatory systems; millenarianisms. 


\section{El miedo como objeto de estudio}

El miedo es una emoción individual, pero también puede ser una experiencia social, colectiva y compartida. Sus múltiples dimensiones permiten que se la pueda analizar con diferentes perspectivas. Las emociones son verdaderamente un tema interdisciplinario que se puede estudiar desde distintos ángulos, tanto desde las ciencias naturales como de las sociales y culturales. Un ejemplo de las diferentes maneras de estudiar el miedo está presente en los volúmenes Fear: across the disciplines (Plamper y Lazier, 2012), La peur et ses miroirs (Viegnes, 2009) y Le monde des émotions (Sander, 2015), por citar solo algunos, que reúnen capítulos escritos por especialistas en neurociencia, biología, filosofía, psicología clínica, teoría política, antropología, historia, estudios literarios... Este interés no es nuevo. Al ser una emoción primaria del ser humano, el miedo ha suscitado cuestionamientos desde la Antigüedad.

Debido a sus numerosas dimensiones y manifestaciones, no es fácil delimitar el concepto de miedo, que se encuentra entre la preocupación y el espanto, el terror y el pánico (Morin, 1993: 131). El miedo puede ser individual o colectivo, espontáneo o deliberado, permanente o cíclico, y aparece en las configuraciones o circunstancias más dispares. Para Edgar Morin (1993), el miedo es un concepto típicamente equívoco, pero esta imprecisión no es necesariamente algo negativo, ya que permite múltiples exploraciones desde diversos puntos de vista.

El miedo es una emoción desagradable causada por la amenaza de peligro, de dolor o de daño. Sin embargo, si lo estudiamos desde la perspectiva antropológica, no podemos reducir el miedo a una emoción individual. Sin duda, las emociones forman parte del individuo, pero, como dice Scruton, las emociones son creaciones culturales, no individuales. Este autor explica que para entender las emociones hay que focalizarse sobre lo que ellas "provocan» y no sobre lo que «son», y que por ello debemos alejarnos del individuo y centrarnos en la experiencia común. Por lo tanto, concluye que si las emociones son experimentadas por los individuos, su significado se puede encontrar solo en nuestra existencia colectiva (Scruton, 1986: 6). Fuertemente influenciados por las creencias y los valores integrados socialmente, los miedos no se pueden estudiar como si estuvieran aislados del mundo social. En otras palabras, el miedo no puede ser estudiado fuera de contexto: el entorno social, cultural y político es fundamental para entender el surgimiento y la gestión de los temores. 
Desde un punto de vista antropológico, aunque un sentimiento puede ser compartido, no es fácilmente accesible a través de los métodos etnográficos. A pesar de la dificultad de «etnografiar el miedo» (véase Jeudy-Ballini y Voisenat, 2004), se pueden percibir las principales preocupaciones de una sociedad y de una cultura a través de las manifestaciones socioculturales de sus miedos compartidos. Algunos peligros, aunque reales, se temen en algunas culturas pero no en otras. Los miedos se definen y se experimentan de manera distinta en las diferentes culturas, e incluso en el interior de una misma cultura. Es por eso por lo que hablamos de miedos, en plural. El sociólogo Frank Furedi sostiene que cada cultura tiene un miedo especial: «In ancient societies, people were taught to fear their gods or ancestors. In medieval times, communities were incited to fear witches and other malevolent supernatural forces. Some cultures fear death, others are concerned about employment» (Furedi, 2007: ix) ${ }^{1}$.

Todos debemos aprender a vivir con la incertidumbre y controlar nuestros miedos. Una perspectiva antropológica conduce las investigaciones y las observaciones hacia lo que los individuos y los grupos temen más y por qué, hacia qué estrategias y mecanismos se utilizan para disipar, afrontar y superar el miedo. En consecuencia, lo que las personas temen y cómo enfrentan los miedos nos enseña mucho sobre una determinada sociedad. Los miedos son espejos en los que se reflejan los valores, las representaciones, las creencias, las ideas y otros elementos esenciales de la sociedad en cuestión.

En este sentido, los capítulos recogidos en el libro The anthropology of fear (2014) ofrecen diferentes ejemplos de cómo la historia y las culturas forjan y alimentan los miedos. Lo que genera el miedo se encuentra en un conocimiento social colectivo, por lo tanto, en la cultura. Lo que interesa al antropólogo son los orígenes del miedo, no tanto el miedo como emoción, sino aquello que lo provoca, los mecanismos que lo favorecen, las situaciones que producen miedo en un momento y un lugar dados. Por lo tanto, el interés antropológico en el miedo no se puede reducir a su aspecto emocional, sino que el análisis se debe centrar en el miedo como respuesta y gestión racional en situaciones peligrosas o consideradas como tales.

1 «En las sociedades antiguas, se enseñaba a la gente a temer a los dioses o a los antepasados. En la época medieval, se incitaba a las comunidades a temer a las brujas y a otras fuerzas malignas sobrenaturales. Algunas culturas temen la muerte, otras se preocupan por el empleo». (Todas las traducciones son personales). 


\section{Miedo, angustia, vulnerabilidad y riesgo}

Aunque las dos nociones son cercanas, el miedo se diferencia de la angustia en que el miedo tiene un objeto (miedo a algo), mientras que la angustia es una emoción sin un objeto definido. La angustia no tiene una causa concreta, su origen es desconocido (Natanson, 2008). El miedo, sin embargo, es una respuesta a la percepción de un peligro que, aunque sea parcialmente imaginario o totalmente ilusorio, siempre se percibe como real. El miedo se podría así explicar como la representación que una persona tiene de su propia vulnerabilidad ligada a la perspectiva del riesgo de una situación. El miedo puede aparecer cuando se tiene una sensación de pérdida de control de los acontecimientos que nos suceden. Por lo tanto, el miedo está ligado a la sensación de vulnerabilidad frente a los peligros. De hecho, sentimos miedo no cuando somos vulnerables, sino cuando nos sentimos vulnerables.

Los temores se construyen a partir de la construcción de riesgos. Dado que los peligros cambian, así como la percepción de los riesgos, lo que consideramos hoy como un riesgo no es lo mismo que en el pasado. Los principales riesgos que amenazaron la humanidad, y por lo tanto los principales temores, tenían como origen un elemento natural: epidemias, malas cosechas, incendios, terremotos. Posteriormente, las guerras fueron tomando un lugar central, y los peligros naturales parecían cada vez menos importantes en comparación con los que inventaron los hombres (Walter, 2008). Por lo tanto, si la percepción de lo que es un riesgo cambia, los temores que este origina cambian también. Por otra parte, como señala Jodelet (2011:243), se puede establecer una tipología de los miedos correspondientes a diferentes riesgos. Como la percepción de los riesgos y el miedo no son objetivos, lo que marca la diferencia entre sentir o no sentir miedo es la percepción de vulnerabilidad frente al peligro.

A menudo se ha tratado al miedo como una emoción negativa que se debe evitar. Pero el miedo es ambiguo. Hay miedos peligrosos y miedos que salvan. «[... ] la peur ne sentend pas forcément comme une expérience négative et indésirable à laquelle les membres d'une société donnée n'auraient de cesse de chercher à se soustraire ou qu'ils viseraient à éradiquer ${ }^{2}$ (Jeudy-Ballini y Voisenat, 2004). El miedo también se puede considerar como una emoción

2 «El miedo no es necesariamente una experiencia negativa e indeseable frente a la cual los miembros de una sociedad dada buscarían incesantemente escapar o la manera de erradicarla». 
positiva, una calidad, a property and an entitlement ${ }^{3}$ como lo sugiere Caroline Humphrey (2013). El miedo a lo desconocido implica curiosidad y espíritu de descubrimiento, que poseen una connotación positiva. El miedo puede ser positivo cuando, por las respuestas que moviliza, puede evitar un desastre y salvar personas.

El miedo es más que una emoción, es también, y sobre todo, una estrategia que puede marcar la diferencia entre seguir vivo o morir. Si el miedo es una emoción tan poderosa es porque está relacionado con la supervivencia: permite reaccionar y encontrar la respuesta adecuada a una situación de peligro. Puede salvar vidas cuando frena la desgracia gracias a la huida. Otra consecuencia típica del miedo es la parálisis. Sin embargo, la parálisis también puede ser una respuesta apropiada para la supervivencia. En todos los casos, siempre se necesita creatividad para encontrar las maneras de superar el miedo.

\section{Los miedos colectivos y los miedos sociales}

Además de los miedos individuales existen los miedos colectivos, que se refieren a las principales preocupaciones compartidas por una comunidad. Cada época y cada cultura tienen sus preocupaciones mayores, los peligros que les importan y en torno a los cuales han construido los temores. Algunos miedos son cíclicos, y aunque no desaparecen por completo, otros se imponen más. En el pasado, hubo el miedo a las hambrunas, a las epidemias, a las guerras. Estos temores están siempre latentes y vuelven a aparecer con fuerza cuando las condiciones se muestran amenazantes. Cuando los miedos colectivos conducen a acciones sociales, como identificar un responsable o un culpable, se convierten en miedos sociales. En otras palabras, la instrumentalización de los miedos colectivos los transforma en miedos sociales.

Los miedos colectivos más conocidos son aquellos estudiados por los historiadores durante los tiempos de epidemias, en particular la peste en la Edad Media en Europa (Delumeau, 1978). Por las reacciones que provocan, estos miedos colectivos se convierten en miedos sociales. La idea de complot es una respuesta dominante durante tiempos de epidemia de cierta gravedad y alimenta los miedos sociales. El temor es que un grupo quiera deshacerse de una parte de la población. Como lo cita Fabre, el temor de «maladies inventées par

3 «Una cualidad y un derecho». 
les riches pour faire mourir les pauvres gens» ${ }^{4}$ (citado por Fabre, 1993: 57). Para los ricos, el mal proviene de los pobres, y el miedo al contagio significa, en primer lugar, el miedo del populacho, que asocian al desorden y a la ruina: la pobreza es esa enfermedad civil y moral, vector de todos los contagios (Fabre, 1993: 65).

En un periodo hubo el miedo a la peste; en otro, al sida. Ayer, el temor que se imponía era el de la bomba atómica, y hoy en día, ¿̇cuál es el miedo que prevalece en las sociedades occidentales? La idea y la esperanza en el progreso, que motivaban a la gente después de la Segunda Guerra Mundial, han sido remplazadas por un miedo generalizado del futuro. Furedi escribió: «It is not hope but fear that excites and shapes the cultural imagination of the early twentyfirst century $»^{5}$ (Furedi, 2007: vii).

Ciertas condiciones sociales y circunstancias específicas favorecen el desarrollo de miedos colectivos. Actualmente, las principales fuentes de preocupación en Europa parecen ser, entre otras, la crisis económica, los conflictos en el mundo, la migración y las catástrofes. El número creciente de desastres, conflictos e incertidumbres alimentan los miedos colectivos y despiertan el miedo de un final que se aproxima. Algunas «grandes cuestiones» han favorecido a menudo el desarrollo de los miedos colectivos: el progreso tecnológico y sus riesgos; el sentimiento de inseguridad, relacionado con el desempleo, pero también con la violencia urbana; las amenazas de la migración en masa; los riesgos ambientales y el futuro del planeta; el terrorismo; el fanatismo; la desconfianza hacia los políticos y la gente en el poder; la propagación de enfermedades, especialmente los virus incontrolables...

Los miedos son múltiples. Aquello que se percibe como una amenaza sobre la sociedad conduce a los miedos colectivos. En tanto que emoción compartida por toda la comunidad, los miedos pueden conducir a una mayor cohesión social. Los miedos colectivos pueden actuar como un catalizador para fortalecer los lazos sociales: la gente se siente unida no tanto porque comparten un mismo idioma, una misma religión o los mismos valores, sino por un sentimiento de miedo compartido. Una forma de propaganda difunde temores construidos y legitimados colectivamente, que se infiltran incluso en los espíritus más recalcitrantes empujando a actuar de manera concertada a un grupo de individuos.

4 «Enfermedades inventadas por los ricos para matar a los pobres».

5 «No es la esperanza sino el miedo lo que excita y modela la imaginación cultural del inicio del siglo xxI». 
A menudo, estos miedos no son el fruto de una experiencia o percepción personal de un peligro, sino el resultado de la difusión de discursos, científicos o no, políticos, públicos, que dan forma a un miedo común, transmitido por varios medios. En esta dinámica, el papel de los medios de comunicación es importante, ya que promueven la aparición de miedos gracias al registro emocional que utilizan para difundir la información y la forma que dan a las preocupaciones sociales (Jodelet, 2011: 245).

Algunos acontecimientos contemporáneos han desencadenado miedos colectivos, como la crisis de la deuda en Europa, la amenaza de recesión económica, las migraciones masivas o el riesgo de una nueva guerra mundial. Sin embargo, los discursos sobre el miedo se perciben de manera distinta por diferentes grupos en diferentes sociedades. El impacto heterogéneo de esta cultura del miedo en las sociedades es un verdadero tema de estudio: ¿por qué la opinión es tan vulnerable a algunos riesgos e insensible a otros fenómenos? ¿Qué mecanismo guía lo que nos tiene que preocupar?

El terremoto seguido del tsunami que arrasó la planta de energía nuclear de Fukushima Daiichi en marzo de 2011 activó inmediatamente los miedos de otros desastres nucleares. Cinco años más tarde, este miedo se ha evaporado en parte, y los temores se dirigen ahora a los conflictos globales y las consecuencias migratorias. La tesis de Furedi es que el miedo está relacionado con los cambios inherentes a la historia y a la cultura. De acuerdo con este autor, la tendencia actual es una sensación general de «estar en riesgo» (to be at risk). Sin embargo, como actores dotados de reflexión, los individuos y los grupos son conscientes de este «clima de riesgo» generalizado y son capaces de reaccionar a él, ya sea a través de una participación activa, una aceptación resignada o un rechazo confuso. Los valores culturales, la identidad, la elección racional o la confianza, según el marco teórico adoptado, permiten determinar la importancia que los individuos o los grupos atribuyen a los diferentes riesgos y los miedos que resultan. 


\section{La identificación de un chivo expiatorio para exorcizar los miedos sociales}

Los miedos sociales ahondan las grietas de la sociedad y conducen a acusaciones. Se supone que, para evitar el flagelo, hay que encontrar al culpable y tratarlo en consecuencia. El culpable designado se convierte en un chivo expiatorio, fuente de todos los males sufridos por la sociedad y responsable de las amenazas sentidas por la comunidad. El chivo expiatorio se convierte en el blanco de todos los resentimientos, donde se focalizan todas las acusaciones y quejas.

El chivo expiatorio ofrece una explicación a las víctimas de la crisis sufrida por la comunidad, él es «el origen del problema». Su eliminación terminará con la crisis y permitirá el retorno a la normalidad. Además, la unión de la comunidad contra el chivo expiatorio fortalecerá los lazos en el interior de la comunidad por el hecho de que se reúnen «todos» contra «uno». El chivo expiatorio se convierte así en una forma de canalizar el miedo: miedo a sentirse amenazado por el «otro», el diferente. Como lo recuerda Gérard Fabre, en el ámbito de la cristiandad medieval, el Otro de quien proviene todo el mal incluye los mendigos, los vagabundos, los nómadas, los judíos: sobre ellos va a caer la ira de las autoridades y de las muchedumbres en tiempos de epidemias (Fabre, 1993: 45).

La desconfianza hacia el Otro es explotada e instrumentalizada en los tiempos favorables a los miedos colectivos. La designación de un chivo expiatorio puede ser hecha por las autoridades o grupos con fines políticos y se utiliza como excusa para despertar la hostilidad contra las minorías o grupos marginalizados. Este mecanismo está todavía presente en la actualidad. La aparición del sida se acompañó de representaciones sociales que se referían a las grandes epidemias del pasado. El miedo colectivo se convirtió en miedo social e identificó en un principio a homosexuales, drogadictos y negros como culpables de la diseminación de la enfermedad.

Una de las consecuencias sociales de los desastres, ya sean originados por un fenómeno natural o por un accidente tecnológico, es la identificación de un responsable. La búsqueda de explicaciones por parte de las víctimas de un desastre suele ir acompañada de una búsqueda de culpables, que pueden fácilmente convertirse en un chivo expiatorio. Buscar una explicación y designar un 
culpable son acciones tranquilizadoras, que delegan la responsabilidad en un error externo.

El análisis de la designación del chivo expiatorio nos permite entender mejor ciertos mecanismos para luchar contra el miedo. La ira se dirige a veces en direcciones que no siempre están relacionadas con la crisis, sino que reflejan hostilidades, desconfianzas y conflictos preexistentes. No es raro que la búsqueda de responsables, la designación de un chivo expiatorio y el castigo popular se vuelvan finalmente un ajuste de cuentas.

En principio, todo el mundo está de acuerdo en que el mecanismo del chivo expiatorio es cruel e injusto, pero se sigue reproduciendo con cambios de forma y de víctima. Hoy como ayer, todas las formas de Otro, ya sea extranjero, árabe o migrante, o bien Otro porque tiene poder y capacidad de tomar decisiones fundamentales, pueden convertirse en chivos expiatorios para alejar o tratar de dominar los miedos colectivos.

\section{Los miedos del final}

Más allá de los miedos particulares, relativos a un momento histórico y a una cultura específica, podemos postular que existe un miedo primario, animal, general, común a toda la especie. Sería como la estructura esencial que permite declinar todos los demás miedos, así como el desarrollo de las culturas del miedo.

Cuando analizamos los miedos teniendo en cuenta las perspectivas históricas y culturales, un miedo fundamental sobresale: el de la muerte. Muchas otras formas de miedo derivan de este temor básico. El miedo al Otro es también uno de los miedos primarios (véase Edgar Morin, 1993). Denise Jodelet contrasta los miedos totales con los parciales. Estos últimos se definen por el conocimiento que se tiene acerca de la fuente del miedo: se refieren a los peligros o riesgos más o menos definidos, y están localizados. En cuanto a los miedos totales, el miedo a la muerte es el paradigma. El temor al Otro también se puede colocar en esta categoría, así como el temor a la «nada» (Kierkegaard) u otros temores indefinidos que pueden adoptar la forma de ansiedad existencial y de angustia (Jodelet, 2011:244).

El miedo a la muerte también se puede traducir como el miedo al fin, a la ausencia, al vacío, a la nada. Es posible conjugar la noción de final en varios 
niveles: a nivel individual, el miedo al propio fin, y a nivel colectivo, el miedo al fin del mundo. El miedo al propio fin acompaña al individuo durante toda su vida, aunque sin ser omnipresente. Frente al miedo a la muerte, el placer de la vida es un «caza-muerte», citando a Edgar Morin (Morin, 1993: 133). En cuanto al temor del fin del mundo, algunas sociedades son más susceptibles que otras, particularmente las que poseen una concepción lineal del tiempo. Jodelet señala que la creencia en el Apocalipsis ha sido y sigue siendo un miedo total que se reactiva por los temores indefinidos que suscita el estado del mundo contemporáneo (2011: 245). Algunas fechas son más propicias para animarlo, como el paso al año 2000 o, más reciente, el 21 de diciembre de 2012, e incluso más cercano, la profecía de la luna sangrienta o luna roja, una profecía de los evangelistas estadounidenses de que la Tierra iba a vivir sus últimos días en septiembre de 2015. La luna sangrienta no era el único suceso, se esperaba también que toda una serie de eventos astronómicos, bíblicos, económicos y políticos eliminarían toda la vida en la Tierra en septiembre de 2015. Todos estos casos eran para advertirnos de que el fin del mundo estaba cerca, o como se explicaba en un sitio milenarista, el fin de nuestro mundo como lo conocíamos. Este sitio (<http://www.historel.net/jclbernard/septembre2015/>), por mencionar solo un ejemplo de las preocupaciones difundidas por la Web, mencionaba no menos de veintidós eventos de tipo astronómico, religioso, político y económico que anunciaban el final. Aquí estamos casi un año después de esa fecha, el fin del mundo aún no se ha producido. Una vez más.

¿Cómo se refleja a nivel colectivo este miedo al fin del mundo? Cuando analizamos el discurso de los promotores del miedo al fin del mundo, nos damos cuenta rápidamente de que es el miedo al fin de un mundo, el que conocemos, acompañado por la esperanza de un mundo nuevo. Es decir, no es siempre el final total y concreto del mundo, sino un final simbólico del mundo que se ha vivido hasta entonces. En tiempos de inseguridad, y cuando el saber científico ya no proporciona respuestas tranquilizadoras, se movilizan todos los recursos interpretativos que ofrecen los sistemas de representación, creencias o los imaginarios sociales (Jodelet, 2011).

Si el miedo al final siempre ha acompañado las sociedades cuyo concepto de tiempo es lineal, en Europa el siglo xx tuvo desde el principio un tono fundamentalmente apocalíptico y de visiones crepusculares. En la búsqueda de explicaciones históricas para comprender nuestros miedos actuales, François Walter 
se interesó en las manifestaciones del miedo desde el principio del siglo xx. En este sentido, menciona los títulos del fin del mundo en la literatura, aquellos en que se habla de tiempos finales y destrucción del mundo, abundantes particularmente en el periodo entre las dos guerras mundiales. También cita las inquietudes expresadas por la filosofía y la literatura alemana, así como la visión y la retórica apocalíptica durante el Tercer Reich, la desaparición del viejo mundo y la aparición de un nuevo reino milenarista. En la expresión artística, también algunas pinturas, como el Guernica de Pablo Picasso, muestran una sensación de angustia y desesperación, así como otras obras que son variaciones sobre el Apocalipsis. El tema de Hiroshima también fue abordado por numerosos pintores y fotógrafos (Walter, 2008: 218).

\section{Los antídotos contra los miedos}

Una crisis social puede suscitar temores y desesperación, pero también puede desencadenar formas de creatividad y abrir nuevas oportunidades. Ni los individuos ni los grupos permanecen pasivos e impotentes frente a los miedos. Para enfrentarlos, la gente desarrolla lo que Edgar Morin llama mecanismos antimiedo (Morin, 1993). Se trata de estrategias para mitigar, apaciguar y enfrentar los miedos, ya que es imposible vivir con un sentimiento permanente de temor. Todo miedo requiere una respuesta, una acción. Morin menciona varios mecanismos antimiedo tranquilizadores. Frente al miedo al otro, realizamos rituales en la vida cotidiana, como los saludos, la cortesía, el pedido de novedades, la charla. «On ne se rend pas compte combien ces rites banalisés sont liés à la peur de l'autre, à l'agressivité latente dans tout rapport avec autrui» (Morin, 1993: $133)^{6}$. Todos los rituales tienen una función tranquilizadora, particularmente necesaria en tiempos inciertos.

Otro mecanismo frente al miedo es aferrarse a la identidad y a las tradiciones. O bien buscar refugio en los orígenes, un retorno a la tierra, al campo. Según el mismo autor: «La tradition ne renvoie pas seulement au passé, comme on l'a toujours pensé pour les sociétés traditionnelles : elle permet aussi d'aller vers le futur, ce qui donne épaisseur et sens au présent. La source ne doit pas mourir, et s'y ressourcer neutralise l'incertitude du futur». (Morin, 1993:

6 «No nos damos cuenta de que estos ritos banales están relacionados con el miedo al otro, a la agresividad latente en toda relación con los demás». 
134) ${ }^{7}$. Sin embargo, confinarse en los límites de la identidad y de las tradiciones, replegarse en la comunidad, también puede ser peligroso. El miedo que aísla a los individuos y los conduce a protegerse en su esfera privada contribuye a la creación de un nosotros que se opone a un ellos, exterior y origen del miedo.

Como ya hemos mencionado, buscar el sacrificio de chivos expiatorios puede servir para exorcizar los temores. El chivo expiatorio representa el Otro, el enemigo, el diferente, que se encuentra en el origen del miedo. Es un alivio identificar lo que se cree que es la fuente del mal. Como el miedo está relacionado con la pérdida y la muerte, apacigua el saber quiénes son los agentes que se pueden destruir para evacuar así el origen del miedo. Sin embargo, existen otros mecanismos como la amistad y la solidaridad. Los tiempos de gran desasosiego generan desconfianzas pero también generosidad, dedicación y participación en la comunidad. La reafirmación del vínculo es también uno de los grandes antídotos contra el miedo (Morin, 1993).

Otro antídoto contra el miedo es la esperanza milenarista, que transforma el miedo en promesa. En un sentido restringido y cristiano, el milenarismo es el conjunto de creencias acerca de la venida de Cristo a la Tierra, en la que reinaría por mil años de felicidad. Esta creencia es el resultado de una lectura del Apocalipsis de Juan. En un sentido más amplio, el milenarismo es la creencia en una edad de oro futura. Los temores de la destrucción se ven compensados por la creencia en un futuro mejor. En tiempos de incertidumbre o de creencias apocalípticas, la esperanza milenarista vence el miedo y permite encontrar certezas. A pesar de que el fin del mundo esté cerca, la creencia milenarista sostiene que este final es el origen de un nuevo paraíso terrestre y la salvación de los justos. Los creyentes en los movimientos milenaristas esperan la transformación de este mundo en un mundo agradable, seguro y placentero, un mundo donde no haya miedo ni sufrimiento.

Los antropólogos y sociólogos de la religión extendieron el significado de milenarismo más allá de su sentido estrictamente cristiano y lo aplicaron por analogía a otros grupos y movimientos, religiosos o no, que esperan una transformación radical del mundo y de la sociedad en que viven. Los movimientos milenaristas, en cuanto representantes de la esperanza de un mundo mejor en

7 «La tradición no se refiere solo al pasado, como siempre lo hemos creído para las sociedades tradicionales: también permite ir hacia el futuro, dando espesor y sentido al presente. El origen no tiene que morir, y recargar las energías en los orígenes permite neutralizar la incertidumbre del futuro». 
esta tierra, también se encuentran en las sociedades que no son cristianas. Peter Worsley utiliza el término milenarista para describir los movimientos en los que se espera y se prepara la llegada de un periodo de felicidad sobrenatural, que no necesariamente debe durar mil años (Worsley, 1957).

Las numerosas investigaciones sobre los milenarismos en Europa y en otros lugares se han centrado en el origen del movimiento y en los tipos de personas que adherían. Se observa así que los movimientos milenaristas surgen con mayor frecuencia en las sociedades en crisis y se desarrollan particularmente en los pueblos que han sido colonizados, en el ámbito de los campesinos descontentos y en los grupos marginales de las ciudades. Sin embargo, estudios más recientes como el de Pascal Bouvier (2008) muestran que las esperanzas milenaristas no se reducen a las poblaciones marginales y del pasado, sino que se pueden encontrar en el centro de algunos movimientos políticos contemporáneos. En la actualidad, el milenarismo excede el marco religioso y el discurso milenarista es utilizado por diferentes grupos, sectas, New Age u otros. El impacto de estas creencias milenaristas es diferente en función de los países, las culturas y las experiencias locales.

$\mathrm{Al}$ ser una creencia que predice una era de felicidad y perfección terrestres, el milenarismo se opone a la sociedad existente, considerada como injusta y opresiva, y proclama su próxima destrucción. La esperanza milenarista es la expectativa de un mundo mejor en un tiempo que será mejor. Los mesianismos y milenarismos se caracterizan por una mezcla de terror y de esperanza. Según estos movimientos, hay que transformar la sociedad actual, fuente de miseria y opresión, y remplazarla por otra que sea «perfecta». Una ruptura es necesaria para realizar un destino tal de la humanidad. Las catástrofes que anuncian el fin del mundo provocan esta ruptura.

Así, las creencias milenaristas actúan como un antídoto contra el miedo. Sin embargo, cuando las grandes expectativas de cambio no se realizan, cuando no se produce la inversión del mundo de oprimidos en un mundo en armonía y sin miedos, la desilusión puede hacer surgir nuevos miedos, que pueden convertirse en miedos sociales, acusadores, amenazando el tejido social.

Otros mecanismos para reducir el miedo han sido desarrollados por una industria de la seguridad ligada a una industria del miedo. Si el miedo no se puede disipar, hay que buscar la seguridad por todos los medios, desde las comunidades cerradas (o barrios cerrados) hasta todos los dispositivos de seguri- 
dad. La sensación de inseguridad está fomentada por algunos sectores para los cuales es rentable la promoción de un nuevo nicho económico que desarrolla dispositivos de seguridad. Furedi (2007) menciona la aparición de empresarios que se benefician de las ansiedades de la gente. Vemos aparecer así una mercantilización del riesgo, donde se comercializan nuevas soluciones individuales para atenuar el riesgo, y por lo tanto sentirse menos vulnerable y reducir de esta manera el miedo.

Además del antídoto milenarista del pasado, encontramos hoy el antídoto del consumo contra todos los miedos. Todo tipo de consumo, de tecnología, de objetos de prestigio, de viajes, de entretenimientos, de dispositivos de seguridad, representa un mecanismo para alejar los grandes miedos y las pequeñas angustias. Si las escatologías de redención son todavía útiles para algunos creyentes, el consumo se ha ido imponiendo como un antídoto mayor contra el miedo y una forma de dominarlo.

\section{La manipulación de los miedos}

Los estudios sociológicos más recientes señalan el sensacionalismo de los medios de comunicación, los políticos e incluso algunos intelectuales en los reportajes sobre la criminalidad, la violencia, las enfermedades y otros problemas sociales. «Perhaps the most consistent conclusion of these recent studies has been that fear is a plague within our society because it is regularly and intentionally misused to further suspect economic, political, or ethnic motives» ${ }^{8}$ (Brissett, 2003). Al ver la larga difusión de miedos, también nos preguntamos: ¿a quién favorece?

Corey Robin es un politólogo de Estados Unidos interesado en el tema del miedo y en su manipulación política. Señala que para Tucídides, el miedo era una de las tres razones para la acción, las otros dos eran el honor y el interés (Robin, 2004). Maquiavelo también abordó el tema del miedo como instrumento de poder y evoca el uso de la amenaza de la destrucción o del miedo al castigo en la dirección de los asuntos políticos. Esta idea encuentra su formulación más completa en las obras de Thomas Hobbes, que pone de relieve el papel del miedo en la formación y el funcionamiento del cuerpo político.

8 «Quizás la conclusión más consistente de estos estudios recientes ha sido que el miedo es una plaga dentro de nuestra sociedad, ya que regular e intencionalmente se lo utiliza de manera abusiva para impulsar motivos económicos, políticos o étnicos sospechosos». 
El poder del miedo es tan grande que se usa y se abusa de él en todo tipo de amenazas para desestabilizar un sistema, una población, un tipo de sociedad. También para mantener un estado de sumisión. El miedo sigue siendo el instrumento preferido por los agentes del poder que tratan de lograr ciertos objetivos mediante la manipulación de las emociones de un público poco o mal informado. El uso extremo del miedo como una herramienta eficaz, acompañado por la violencia, para alcanzar objetivos políticos es evidente en el terrorismo y los actos terroristas.

Hoy como ayer, los miedos y sus antídotos son manipulados para establecer una forma de poder. La política es un lugar privilegiado para observar la influencia de los discursos que utilizan el miedo. Hay que tener cuenta, sin embargo, que los actores sociales reaccionan de manera diferente, sobre la base de sus conocimientos y sus representaciones, a las amenazas dirigidas por los discursos políticos y los medios de comunicación. Los actores sociales son capaces de reflexividad y de imaginación que permiten la acción y la reacción.

\section{Conclusión}

Vivimos con miedo. No podemos saber si hay más miedos hoy que en el pasado, pero sí que hay una mayor sensibilidad al riesgo. La vulnerabilidad social se ha incrementado y los miedos se multiplicaron con la globalización. En un mundo globalizado, la velocidad del flujo de información, a veces distorsionada, altera nuestra percepción y la conciencia del peligro. Este es un contexto que fomenta la aparición de miedos colectivos.

A través del prisma de los medios de comunicación, eventos lejanos influyen en nuestra percepción de lo cotidiano. Los ataques terroristas, las catástrofes, los conflictos armados, las amenazas nucleares, así como riesgos menores cotidianos que aparecen en la prensa, nos han vuelto más sensibles a los riesgos que podemos correr, y la conciencia de esta fragilidad nos asusta y nos da miedo.

Gracias a su capacidad de proyectarse en el futuro, el ser humano puede sentir miedo de cosas que no lo amenazan en lo inmediato. Nuestro mundo de hoy ha producido un cierto número de amenazas ecológicas, tecnológicas y militares cuyas consecuencias pueden ser trágicas. La modernidad nos condujo a una zona de turbulencia, con riesgos que pueden poner en peligro la vida del planeta. Frente a esto, los miedos prosperan. Cuanto más se desarrolla la 
tecnología, mayor es el riesgo, y mayor es el miedo. Hasta el punto de que podemos afirmar finalmente que nuestras propias obras nos inquietan.

En un periodo no muy lejano, el riesgo de todo tipo -industrial, financiero, profesional- era muy bien valorado, pero poco a poco se comenzó a valorar la seguridad (de las inversiones, del empleo, de las ciudades). La sensibilidad frente al riesgo y la necesidad de seguridad aumentaron en forma exponencial en los últimos años. Esta necesidad de seguridad y la creciente sensación de miedo van a la par.

El mensaje es paradójico. Los riesgos están en todas partes: hay que tener miedo de la comida, de la ciudad, de los suburbios, de las centrales nucleares, de los productos químicos, de los jóvenes, de los terroristas... Los miedos colectivos se convierten en miedos sociales cuando son alimentados por la idea del complot. La falta de perspectiva y de actitud crítica favorece el desarrollo de una sociedad paranoica. En los últimos años se desarrolló en las principales ciudades de Europa una situación de pánico debido a la inseguridad, que condujo a una «cultura del miedo». La inseguridad también provoca la desconfianza en las relaciones, tanto públicas como privadas, y un deterioro en el arte de vivir juntos y mostrar solidaridad. Este sentimiento de inseguridad es, además, explotado por algunos sectores a quienes es muy rentable. Y mientras desde algunas partes se fomenta el miedo, se recibe el mensaje tranquilizador desde la cúpula política, que proclama: «No hay que tener miedo, todo está bajo control».

El poder psicológico y social del miedo es tal que no faltan políticos sin escrúpulos que construyen su poder sobre la promoción del miedo. Más aún, es posible fomentar la sensación de miedo y aprovecharse de ello presentándose como un «salvador». De esta manera, en los sistemas paternalistas, el poder político se encarga de maximizar la difusión de los posibles peligros y se presenta paralelamente adoptando un rol protector. Por otra parte, en un momento en que la confianza de los ciudadanos en las instituciones y sistemas políticos disminuye, aumentar la conciencia del riesgo y presentarse al mismo tiempo como garante de la seguridad, podría ser una maniobra para recuperar esa confianza.

El creciente temor al islam deriva de la idea de que amenaza la civilización cristiana europea y la democracia. Sin embargo, el miedo también podría ser una amenaza para la democracia y las libertades. Dentro de este sector de la 
antropología del miedo, se deberían conducir más investigaciones, sobre todo en cuanto a la instrumentalización del miedo con el fin de demonizar al Otro. El pasaje a un sistema acusatorio es un peligro que hay que evitar.

\section{Bibliografía}

Angenot, M. (1998). «C'est l'éruption de la fin! Le diagnostique crépusculaire, un genre culturel français des années $80 »$, In: Laurier Turgeon (dir.), Les entre-lieux de la culture. L'Harmatan, 29-55.

Boscoboinik, A. y Horáková, H. (eds.) (2014). The anthropology of fear, Cultures beyond emotions. LIT Verlag.

Bouvier, P. (2008). Millénarisme, messianisme, fondamentalisme: permanence d'un imaginaire politique. L'Harmattan.

Brissett, W. N. (2003). «Bibliographical Essay on Fear». The Hedgehog Review / Fall 03, 115-123.

Delumeau, J. (1978). La peur en Occident (xive - xvirie siècles). Une cité assiégée. Fayard.

Fabre, G. (1993). «Conflits d'imaginaires en temps d'épidémie». Communications, n. ${ }^{\circ} 57,43-70$.

Furedi, F. (2007 [1997]). Culture of Fear Revisited. Risk-taking and the Morality of Low Expectation. London: Continuum.

Humphrey, C. (2013). «Fear as a Property and an Entitlement». Social Anthropology, 21: 3, 285-304.

Jeudy-Ballini, M. y Voisenat, C. (2004). «Ethnographier la peur». Terrain, Numéro 43 - Peurs et menaces, 5-14.

Jodelet, D. (2011). «Dynamiques sociales et formes de la peur». Nouvelle revue de psychosociologie 2/2011 ( n. $\left.^{\circ} 12\right)$, pp. 239-256. URL: <www.cairn. info/revue-nouvelle-revue-de-psychosociologie-2011-2-page-239.htm >.

Morin, E. (1993). «Les anti-peurs». Communications, n. ${ }^{\circ}$ 57, 131-139.

Natanson, J. (2008). «La peur et l'angoisse». Imaginaire E Inconscient, 2008/2, n* 22 , pp. 161-173.

Plamper, J. y Lazier, B. (eds.) (2012). Fear: Across the disciplines. University of Pittsburgh Press.

Robin, C. (2004). Fear: The History of a Political Idea. Oxford University Press. Sander, D. (dir.) (2015). Le monde des émotions, éditions Belin. 
Scruton, D. L. (1986). «Introduction». En Scruton D. (ed.) Sociophobics. The Anthropology of Fear. Boulder and London: Westview press.

Viegnes, M. (ed.) (2009). La peur et ses miroirs. Ed. Imago.

Walter, F. (2008). Catastrophes, une histoire culturelle XVI-XXI siècle. Seuil.

Worsley, P. (1957). The Trumpet Shall Sound: A study of cargo cults in Melanesia. MacGibbon and Kee. 